Article

\title{
The Impacts of Flowering Time and Tillering on Grain Yield of Sorghum Hybrids across Diverse Environments
}

\author{
Xuemin Wang ${ }^{1, *(D)}$, Colleen Hunt ${ }^{1,2}$, Alan Cruickshank ${ }^{2}$, Emma Mace ${ }^{1,2}$, Graeme Hammer $^{3}$ (D) \\ and David Jordan $1, *$ \\ 1 Queensland Alliance for Agriculture and Food Innovation, The University of Queensland, Warwick 4370, \\ Australia; Colleen.Hunt@daf.qld.gov.au (C.H.); emma.mace@daf.qld.gov.au (E.M.) \\ 2 Department of Agriculture \& Fisheries, Warwick 4370, Australia; Alan.Cruickshank@daf.qld.gov.au \\ 3 Queensland Alliance for Agriculture and Food Innovation, The University of Queensland, Brisbane 4072, \\ Australia; g.hammer@uq.edu.au \\ * Correspondence: xuemin.wang@uq.net.au (X.W.); david.jordan@uq.edu.au (D.J.); Tel.: +61-7-45426722 (X.W.)
}

Received: 3 December 2019; Accepted: 13 January 2020; Published: 16 January 2020

\begin{abstract}
Sorghum in Australia is grown in water-limited environments of varying extent, generating substantial genotype $\times$ environment interactions (GEIs) for grain yield. Much of the yield variation and GEI results from variations in flowering time and tillering through their effects on canopy development. The confounding effects of flowering and tillering complicate the interpretation of breeding trials. In this study, we evaluated the impacts of both flowering time (DTF) and tillering capacity (FTN) on the yield of 1741 unique test hybrids derived from three common female testers in 21 yield testing trials (48 tester/trial combinations) across the major sorghum production regions in Australia in three seasons. Contributions of DTF and FTN to genetic variation in grain yield were significant in 14 and 12 tester/trial combinations, respectively. The proportion of genetic variance in grain yield explained by DTF and FTN ranged from $0.2 \%$ to $61.0 \%$ and from $1.4 \%$ to $56.9 \%$, respectively, depending on trials and genetic background of female testers. The relationship of DTF or FTN with grain yield of hybrids was frequently positive but varied across the genetic background of testers. Accounting for the effects of DTF and FTN using linear models did not substantially increase the between-trial genetic correlations for grain yield. The results suggested that other factors affecting canopy development dynamics and grain yield might contribute GEI and/or the linear approach to account for DTF and FTN on grain yield did not capture the complex non-linear interactions.
\end{abstract}

Keywords: flowering time; genotype and environment interaction; grain yield; sorghum; tillering capacity; water stress

\section{Introduction}

In rain-fed environments, crops rely on within-season rainfall and the stored water accumulated during a previous fallow [1,2]. Varying in depth and water holding capacity, soils can generally accumulate a small proportion (e.g., 25\%-30\% in Australia) [2] of the precipitation received during the fallow period and rarely store adequate water for a crop to produce grain without some rainfall during the growing season [1]. This often results in cereal crops grown in various water-limited conditions [3-7], especially in terminal water stress conditions when soil moisture is depleted during the grain-filling period due to limited in-season precipitation.

Plant researchers have successfully classified crop growing environments into different environment types (ETs) based on the temporal dynamics of a crop water stress index [3,6-9], which is the ratio of potential soil water uptake to crop water demand. These ETs, which vary 
in frequency across regions and seasons, generate differing scenarios of water availability for crop breeding programs. The range of water availability in different ETs and the associated range in timing and intensity of water shortage generate substantial genotype $\times$ environment interactions (GEIs) across locations and seasons [10]. Cereal crop improvement in dryland conditions is substantially impeded by the complexity of GEIs that re-rank genotypes across environments $[7,10,11]$. Plant breeders can use one of two strategies, either ignore GEIs and select for broad adaptation or exploit the interactions by selecting for specific adaptation to types of environments. An understanding of the causes of the GEIs can be useful for designing breeding strategies and agronomic approaches for either scenario.

The impact of water stress on grain yield varies depending on the physiological stage of the crop at which it occurs and the intensity of the water stress [8]. For example in sorghum, grain yield under drought conditions is highly influenced by the temporal water use patterns between pre- and post-anthesis stages [12-14]. In water-limited environments, when a total of only $150 \mathrm{~mm}$ water is available during the whole crop life cycle, a sorghum crop will produce only about $1.6 \mathrm{tha}^{-1}$ of grain if all water is used by anthesis and no water remains for use after anthesis. However, if $60 \mathrm{~mm}$ of water is shifted from pre-anthesis to post-anthesis by changes in management or genetics, grain yield can be more than doubled, potentially achieving $3.5 \mathrm{t} \mathrm{ha}^{-1}$ [14].

While flowering and tillering are traits with high repeatability, they may interact in a complex way with the growing environment to affect the timing and intensity of water stress during the crop life cycle via their effects on canopy development dynamics and hence generate GEIs for grain yield. Flowering time is related to two important canopy development attributes, total plant leaf area and canopy leaf area expansion rate, through the effects of leaf number and leaf appearance rate $[15,16]$, which in turn are substantially influenced by photoperiod and temperature [15]. Tillering, on the other hand, can change canopy size by introducing more culms per plant [17-19]. Non-productive tillers normally cease leaf area expansion early in the crop life cycle and die consecutively between full expansion of the final leaf on the main culm and plant maturity, therefore having minor effects on canopy size $[20,21]$. In contrast, tillers that continue to grow and become fertile may account for up to $63 \%$ of leaf area index [17].

Thus, phenotypic variations in flowering time [22] and tillering [23] can complicate the interpretation of breeding trials and the selection of superior parents for hybrid production. To improve the accuracy of selection in sorghum breeding programs, it will be beneficial to minimise these confounding effects of flowering time and tillering on grain yield. Although the impact of flowering time on sorghum grain yield has been reported in some early research $[24,25]$, those studies were conducted only on dozens of hybrids and in a limited number of environments. Similarly, although the contribution of fertile tiller number per plant (FTN) to grain yield has been investigated by growing a single hybrid at various densities [21], FTN is not normally incorporated into the analysis of yield of a crop breeding program due to the intensive labour requirement for data collection.

Conceptually, flowering and tillering contribute to GEI in sorghum trials [8] but their contribution has not been determined directly. This study aims to examine (1) how much genetic yield variation is due to variations in DTF or FTN, and (2) the relationships of DTF and FTN to grain yield, across diverse environments varying in water availability using data from large-scale yield testing trials. These trials involved a large number of elite male parents and $F_{1}$ hybrids grown across the major sorghum production regions in Australia during the 2015-2017 summer growing seasons. The proportions of genetic variation in grain yield explained by linear mixed models, including DTF or FTN as a fixed effect, were determined. 


\section{Materials and Methods}

\subsection{Breeding Trials}

A total number of 1741 unique hybrids were grown in 21 trials at 15 locations across the major sorghum growing regions of central Queensland (CQ), southern Queensland (SQ), and northern New South Wales (NNSW) in the three consecutive summer growing seasons of 2015-2017. Hybrids were derived from crosses between 1078 elite male parents and three female testers at both the preliminary (PYTMales) and advanced yield testing (AYTMales) stages of the Australian sorghum pre-breeding program [1]. Trials were arranged in partially replicated designs [26] with around $23 \%-35 \%$ of hybrids replicated at least twice (Supplementary Table S1). A different design was used in each individual trial to reduce the possibility of error effects due to spatial variations specific to each trial [1]. The number of hybrids grown per trial ranged from 445 to 925 depending on the season and location, with entries in the trials including both test hybrids and a range of commercial hybrids. Seventeen to twenty-five percent of test hybrids were replicated twice per trial, while the remaining test hybrids were not replicated and commercial hybrids were replicated from once to twelve times depending on the trial. All plots consisted of two rows of 5-metre length. The trials used a solid row configuration. Row spacing was 0.76 metre for 2015 trials at Warwick and Gatton, and 2015-16 trials at Blackville, Warwick and Pirrinuan, whereas it was 1 metre for the other trials. Trials were managed according to local management practices [8]. Trials are indicated by a combination of trial type ("AYTM" for AYTMales and "PYTM" for PYTMales), season (such as "16" for 2016), and location (such as "WAR" for Warwick). The details of the trials are presented in Supplementary Table S1.

The PYTMales trial at Warwick in 2015 (PYTM15WAR) was in the first-year yield testing scheme of the pre-breeding program. The male lines evaluated in the AYTMales trials were either advanced from PYTMales trials with poor performing lines removed or retested from AYTMales trials in the previous years. The male lines advanced from this early-stage selection still possessed substantial genetic variance for grain yield, flowering and tillering capacity. In each season, the plan was to produce a complete factorial combination of hybrids by crossing all males to all three female testers in 2015 and two of them, B963676 and B986604, in 2016 and 2017. The actual number of hybrid combinations that were evaluated in a specific season and location was constrained due to failures in seed production. There was no planned selection for or against certain combinations of females and males. Different sets of males were assessed in different seasons but with a number of males in common between years. Some males were tested in a single season and then removed from further testing due to bad performance, whereas others were evaluated in all three seasons. The male lines shared various levels of ancestry as they included many sets of siblings from the same bi-parental crosses.

Flowering time (days to flowering after sowing, DTF), defined as the number of days from sowing to the time when $50 \%$ plants in the plot had flowered halfway down the panicle, was recorded in each plot. The number of plants and fertile tillers bearing grain was manually counted after maturity on a 1-metre length of row to obtain the average number of fertile tillers per plant (FTN) per plot. Establishment of each plot was scored on a 1-9 scale after either emergence or maturity, with 1 indicating very good establishment and 9 indicating no established plants. Plots were harvested separately after maturity and the grain weight per plot was recorded automatically by the plot harvester and later converted to tonnes per hectare.

\subsection{Data Analysis}

DTF and FTN were collected in 17 and 11 of the 21 trials. Spatial variations in DTF, FTN, and grain yield were accounted for in each trial and a variance structure was subsequently generated to create correlations between trials in a factor analytic (FA) framework [27]. Establishment is an important factor influencing tillering and grain yield; therefore, establishment was fitted as a covariate into the analysis to adjust for its effects on FTN and grain yield. Together with a genetic variance per trial derived from the analysis, FA loadings were obtained and used to create a pair-wise correlation matrix 
across the trials. GEI for each trait was quantified by considering the correlation matrix between trials [1]. Genetic correlations of DTF across the 17 trials ranged from 0.29 to 1 , with a mean value of 0.66 , whereas the genetic correlation of FTN across the 11 trials ranged from 0.41 to 1 , with a mean value of 0.76 (Supplementary Figure S1). These results indicated low G $\times$ E interactions for the two individual traits, suggesting that an overall BLUP (best linear unbiased prediction) for DTF and FTN from the analyses of multi-environment trials (MET) could be used to indicate the flowering time and tillering capacity, respectively, for each hybrid across all trials. Therefore, MET analysis was conducted for each trait and the overall BLUPs for DTF and FTN were predicted for each genotype to determine the impact of DTF and FTN on yield. In contrast, between-trial genetic correlations for yield adjusted for establishment varied from -0.71 to 0.62 with an average of 0.08 (Supplementary Figure S1; Supplementary Table S2), which suggested substantial G $\times$ E interactions for grain yield and hence an overall BLUP for grain yield could not be used to indicate hybrid yield potentials across trials. Thus, it was appropriate to use individual trial estimates of hybrid grain yield to investigate its relationships with DTF and FTN. Repeatability was estimated according to the formula of [26] due to the implementation of spatial models in this study.

The three female testers used in this study, B010054, B963676, and B986604, were originally selected to provide contrasting levels of stay-green. Stay-green is an important trait that can affect tillering and grain yield. While they share varying degrees of ancestry, the three testers also vary in tillering, yield potential, and slightly in flowering (Table 1). Hence, female testers are likely to confound the relationships of flowering time and tillering on grain yield. Therefore, to quantify the contribution of DTF and FTN to the genetic variance of grain yield (hereafter referred to as "genetic yield variance"), male lines were modelled within female testers to avoid the confounding effects of female testers to the relationships of DTF and FTN to grain yield. Firstly, initial genetic yield variances of males within each tester were estimated by setting effects of males within testers (Male|Tester) as a random term in Model 1 (initial model). DTF and FTN were fitted individually into the models for yield analysis. While the three female testers have different levels of stay-green, tillering potential, and yield potential, they were expected to display different general combining abilities for the latter three traits, which could probably confound the impacts of DTF and FTN on grain yield investigated in this study. Therefore, effects of DTF (DTF|Tester) and FTN (FTN|Tester) were fitted as a fixed effect within female testers in Models 2 and 3, respectively. After accounting for the spatial variation in yield, genetic yield variance of males within each tester was quantified. The proportion of genetic yield variance of males within each tester due to variations in DTF and FTN was subsequently calculated according to Equations (1) and (2), respectively.

\footnotetext{
Yield $=$ TestGeno + establishment + Tester + Male|Tester + spatial variation + residuals (Model 1),

Yield $=$ TestGeno + establishment + Tester + Male|Tester + DTF $\mid$ Tester + spatial variation + residuals $($ Model 2),

Yield $=$ TestGeno + establishment + Tester + Male|Tester + FTN|Tester + spatial variation + residuals $($ Model 3),
}

where TestGeno is a vector of logical variables with "yes" representing the male parent of a test hybrid and "no" representing a commercial hybrid; establishment is a score of 1-9 indicating the establishment of a plot.

Proportion of genetic yield variance contributed by DTF

$$
\begin{aligned}
& =\frac{\text { Genetic yield variance_Model 1-Genetic yield variance_Model } 2}{\text { Genetic yield variance_Model } 1} \\
& \times 100 \%
\end{aligned}
$$

Proportion of genetic yield variance contributed by FTN

$$
\begin{aligned}
& =\frac{\text { Genetic yield variance_Model 1-Genetic yield variance_Model } 3}{\text { Genetic yield variance_Model } 1} \\
& \times 100 \%
\end{aligned}
$$

where Genetic yield variance_Model 1, Genetic yield variance_Model 2, and Genetic yield variance Model 3 are the genetic yield variances estimated from Models 1, 2, and 3 respectively. 
To assess the relationship of DTF or FTN to grain yield of sorghum hybrids in production environments, hybrids were grouped within female testers to remove the main effects of testers on DTF, FTN, and grain yield. The effects of female testers, DTF, and FTN were fitted as fixed terms, whereas the effects of hybrids and spatial variation were considered as random terms in Models 4 and 5.

Yield $=$ establishment + Tester.present + Tester $+\mathrm{B}_{1} \times$ DTF $\mid$ Tester + hybrids + spatial variation + residuals $($ Model 4$)$,

Yield $=$ establishment + Tester.present + Tester $+B_{2} \times$ FTN|Tester + hybrids + spatial variation + residuals (Model 5),

where Tester.present indicates the presence of female testers, with "yes" for test hybrids and "no" for commercial hybrids; $B_{1}$ and $B_{2}$ are the regression coefficients of DTF and FTN on grain yield respectively.

For each trial, a mixed model was implemented in the asreml package [28] in R software in Rstudio $[29,30]$ for the analysis. Wald tests were conducted to evaluate the significance of the genetic yield contribution by DTF or FTN and the relationships of the two traits to yield.

As only three and two hybrids were involved from crosses with female B010054 and B986604, respectively, for trial PYTM15WAR, the regression coefficients of DTF and FTN on yield for hybrids of these two testers in that trial were not reported. Therefore, the regression coefficients $\left(B_{1}\right.$ and $\left.B_{2}\right)$ from the remaining 48 tester/trial combinations were presented and plotted against the mean yield of all hybrids within the corresponding tester/trial combinations.

Table 1. Quantitative comparisons of stay-green rating, flowering time (DTF), fertile tiller number per plant (FTN), and yield potential for the three female testers. Stay-green was visually rated from 1 to 9 , with 1 indicating less than $10 \%$ green leaves and 9 indicating over $90 \%$ green leaves.

\begin{tabular}{|c|c|c|c|c|c|c|c|c|c|c|}
\hline \multirow{2}{*}{$\begin{array}{l}\text { Female } \\
\text { Parent }\end{array}$} & \multicolumn{3}{|c|}{ Stay-Green Rating } & \multicolumn{3}{|c|}{$\begin{array}{c}\text { DTF } \\
\text { (Days after Sowing) }\end{array}$} & \multirow{2}{*}{$\begin{array}{c}\begin{array}{c}\text { FTN } \\
\text { (Tillers Plant }^{-1} \text { ) }\end{array} \\
\text { Overall }\end{array}$} & \multicolumn{3}{|c|}{$\begin{array}{l}\text { Yield Potential } \\
\quad\left(\mathrm{t} \mathrm{ha} \mathbf{a}^{-1}\right)\end{array}$} \\
\hline & 2015 & 2016 & 2017 & 2015 & 2016 & 2017 & & 2015 & 2016 & 2017 \\
\hline B010054 & 1.9 & $-a$ & - & 55.5 & - & - & 0.4 & 4.34 & - & - \\
\hline B963676 & 3.5 & 5.7 & $3.8^{b}$ & 55.5 & 64.3 & 71.3 & 0.5 & 5.50 & 5.03 & 4.21 \\
\hline B986604 & 3.6 & 5.3 & $3.7^{b}$ & 55.1 & 63.6 & 70.4 & 0.9 & 5.47 & 5.02 & 4.14 \\
\hline
\end{tabular}

${ }^{a}$ B010054 hybrids were not grown in the 2016 and 2017 seasons; ${ }^{b}$ stay-green ratings of B963676 and B986604 in 2017 were estimated from one single trial in the 2017 season as the phenotype was only expressed in that trial.

\subsection{Environment Type (ET) Simulation}

ET of the breeding trial was simulated using a standard check hybrid with weather data (i.e., temperature, rainfall) collected from the on-site weather station using the latest version of the sorghum module [31] implemented in the APSIM platform [32]. Plants of the check hybrids were tagged after emergence to count the total number of leaves. Together with flowering time, the total number of leaves was used to check the fitness of the phenology and development parameters of the check hybrids used in the simulation. Plant biomass of the check plots was measured at flowering and maturity and separated into green leaves, dead leaves, stem (including leaf sheath), panicles, and grains to adjust for the initial soil moisture at sowing. Soil samples were taken from check plots at sowing and after maturity to measure the available soil moisture to the crop. We aimed to collect data of weather, soil and biomass from all breeding trials. However, some on-site weather stations were faulty, e.g., damaged by wild animals. Due to the workload and travelling distances to the breeding trials, soil and biomass data were also not collected for some trials. By the end, only 12 trials had all the data needed to simulate the ETs. The ET experienced by the standard check hybrid in that trial was used as an estimate of the ET experienced by the corresponding trial. Based on simulations, five ETs have been reported in sorghum growth conditions in Australia: there was no or low water stress occurred throughout the life cycle in ET1; mild water stress did not occur until after flowering in ET2, while the onset of water deficit commenced during flowering in ET5 and was early and severe in ET4; in comparison, although ET3 had an early onset of water stress, the deficit was alleviated after flowering $[7,8]$. 


\section{Results}

\subsection{Phenotypic Evaluations}

Due to the workload and travelling distances to the trials, we were not able to collect data of DTF and FTN for some trials. DTF data were collected for 17 of the 21 trials. A wide range of DTF was observed for the 17 trials. Differences in DTF of the latest and earliest genotypes within individual trials varied from 10 to 20 days, with average DTF varying from 48.4 to 81.7 days after sowing (Table 2). Repeatability for DTF was consistently high, varying from $60.5 \%$ to $87.8 \%$ across the trials with a mean of $72.2 \%$ (Figure 1A). As DTF of the three testers was very similar (Table 1), with less than one-day difference, and the inheritance of DTF is predominantly additive, their corresponding hybrids differed little in average DTF within individual trials (Supplementary Figure S2).

Table 2. Summary of yield, flowering time (DTF), and fertile tiller number per plant (FTN) for the 21 trials. The trials were sorted in ascending order for mean grain yield.

\begin{tabular}{|c|c|c|c|c|c|c|}
\hline \multirow[t]{2}{*}{ Trial } & \multicolumn{2}{|c|}{$\begin{array}{l}\text { Yield } \\
\left(\mathrm{t} \mathrm{ha} \mathbf{a}^{-1}\right)\end{array}$} & \multicolumn{2}{|c|}{$\begin{array}{c}\text { DTF } \\
\text { (Days after Sowing) }\end{array}$} & \multicolumn{2}{|c|}{$\begin{array}{c}\text { FTN } \\
\text { (Tillers Plant }^{-1} \text { ) }\end{array}$} \\
\hline & Mean & Range & Mean & Range & Mean & Range \\
\hline aytm16EME & 2.63 & $0.00-8.07$ & 49.0 & $45-60$ & $\mathrm{na}^{\mathrm{a}}$ & na \\
\hline aytm16ORI & 2.90 & $0.07-6.39$ & 58.0 & $51-64$ & na & na \\
\hline aytm15CAP & 3.01 & $1.08-4.57$ & 51.9 & $46-58$ & na & na \\
\hline aytm15EME & 3.13 & $1.00-6.10$ & 48.4 & $44-55$ & 0.5 & $0.0-1.0$ \\
\hline aytm17CAR & 3.59 & $1.00-6.60$ & 69.2 & $64-84$ & 0.2 & $0.0-1.5$ \\
\hline aytm17MAC & 3.97 & $1.60-6.10$ & 76.4 & $68-79$ & na & na \\
\hline aytm15JIM & 4.34 & $1.50-7.00$ & 58.3 & $53-65$ & 0.2 & $0.0-1.8$ \\
\hline aytm17PIN & 5.18 & $1.00-8.70$ & 71.0 & $68-84$ & 0.3 & $0.0-2.5$ \\
\hline aytm16JAN & 5.32 & $1.42-7.89$ & 57.9 & $51-66$ & 0.2 & $0.0-1.5$ \\
\hline aytm16CRO & 5.76 & $2.66-8.33$ & 71.6 & $66-81$ & 0.4 & $0.0-2.3$ \\
\hline aytm16SPR & 6.24 & $0.00-21.30$ & na & na & na & na \\
\hline aytm17EME & 6.07 & $0.00-8.46$ & 58.8 & $54-66$ & na & na \\
\hline aytm15GAT & 6.27 & $3.10-9.30$ & 63.2 & $60-74$ & na & na \\
\hline aytm16PIR & 6.44 & $3.11-9.01$ & na & na & 0.8 & $0.0-3.3$ \\
\hline aytm16DAL & 6.59 & $1.28-9.22$ & 67.5 & $62-78$ & 1 & $0.0-3.0$ \\
\hline aytm15SPR & 6.84 & $2.20-10.10$ & na & na & na & na \\
\hline aytm15WAR & 6.97 & $3.10-10.10$ & 74.3 & $68-78$ & 0.4 & $0.0-2.7$ \\
\hline aytm16WAR & 7.25 & $2.64-12.66$ & 65.7 & $62-75$ & 1.2 & $0.0-5.0$ \\
\hline aytm15DAL & 7.30 & $1.40-10.80$ & na & na & na & na \\
\hline pytm15WAR & 7.58 & $3.01-11.08$ & 73.0 & $67-77$ & 0.6 & $0.0-3.0$ \\
\hline aytm16BLA & 8.10 & $2.57-13.21$ & 81.7 & $70-90$ & na & na \\
\hline
\end{tabular}

${ }^{a}$ Data not available due to workload and distance travelling to these trials.

FTN data were collected for 11 of the 21 trials. A wide range of FTN was observed for the 11 trials. Differences in FTN of the highest and lowest tillering hybrids in individual trials varied from 1.0 to 5.0 fertile tillers per plant (Table 2). Repeatability for FTN was moderately high, varying from $41.4 \%$ to $70.7 \%$, with an average of $60.7 \%$ (Figure 1). High tillering tester parents tend to produce hybrids with more tillers; FTN of B010054 hybrids was the lowest, while that of B986604 hybrids was generally the highest (Table 1; Supplementary Figure S3).

The mean yield of the 21 trials varied between 2.63 and $8.10 \mathrm{t} \mathrm{ha}^{-1}$ with an average of $5.5 \mathrm{t} \mathrm{ha}^{-1}$ (Table 2), which was consistent with the range of yields commonly observed in sorghum pre-breeding trials [1]. Repeatability of yield adjusted for establishment ranged from $20.6 \%$ to $77.1 \%$, with an average of 55.6\% (Figure 1A). The mean yield of hybrids derived from the tester B010054 was consistently lower than that of hybrids from the other two testers in the 2015 trials, whereas the relative yield of hybrids within the other two female testers varied across years and locations (Supplementary Figure 
S4). This was consistent with the yield potential of the three testers as B010054 had the lowest yield potential, while the yield of B963676 and B986604 were similar (Table 1).

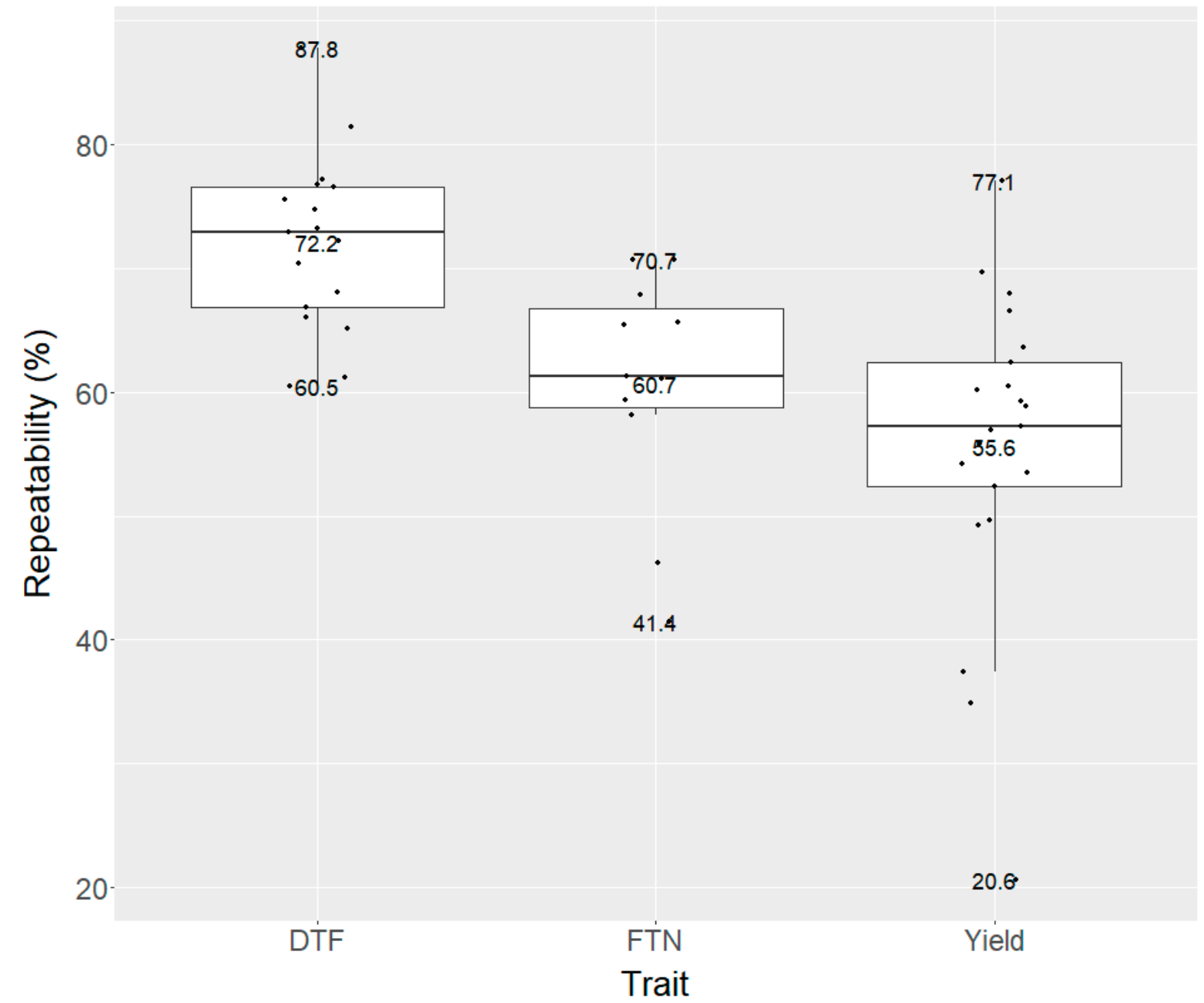

Figure 1. Repeatability of flowering time (DTF), fertile tiller number per plant (FTN) and grain yield. The values above, in, and below each box indicate the maximum, mean and minimum repeatability, respectively.

Correlations between overall BLUPs for DTF and FTN for hybrids across the three testers were not significant, ranging from -0.049 to -0.030 (Table 3). Similarly, non-significant correlations between the two traits were observed in almost all tester/trial combinations except in 4 B963676/trial combinations. However, for those 4 B963676/trial combinations, coefficients of determination $\left(r^{2}\right)$ were less than $1.21 \%$ (Supplementary Table S3). Therefore, these results indicated that DTF and FTN were independent traits, which justified the method of fitting the two traits individually into the models for yield analysis.

Table 3. Correlation between overall BLUPs for flowering time (DTF) and fertile tiller number per plant (FTN) for hybrids in combination with the three female testers. Overall BLUPs for DTF and FTN were predicted from the multi-environment trial (MET) analysis of the 17 and 11 trials, respectively, which had DTF and FTN data.

\begin{tabular}{ccc}
\hline Female & Correlation Coefficient & $\boldsymbol{P}$-Value \\
\hline B010054 & -0.030 & 0.65 \\
B963676 & -0.047 & 0.10 \\
B986604 & -0.049 & 0.19 \\
\hline
\end{tabular}




\subsection{Impact of DTF on Grain Yield}

Genetic yield contribution by DTF of male lines was significant in 15 of the 48 tester/trial combinations (Table 4). Therefore, the proportion of genetic yield variance explained by models including DTF as a fixed effect can only be accurately estimated in these 15 tester/trial combinations. Absolute values of the genetic yield contribution by DTF differed across trials and females, ranging from $0.2 \%$ to $61 \%$, with an average of $13.6 \%$ in those tester/trial combinations with a significant DTF contribution.

Linear regression analysis showed that a statistically significant association between DTF and grain yield of hybrids was observed in 22 tester/trial combinations, of which 14 were positive (Table 4). This general trend towards a positive association between flowering time and grain yield was observed in the data set as a whole, with coefficients being positive on 30 (i.e., 62.5\%) of the 48 occasions. Significant associations between DTF and yield were observed in 14 tester/trial combinations that had environment type (ET) estimated, of which 10, 1, and 3 tester/trial combinations experienced ET1, ET2, and ET5, respectively. A significantly positive relationship was observed in 7 of the 10 tester/trial combinations that had ET1 and the one that had ET2, whereas a negative relationship was observed in all 3 tester/trial combinations that had ET5.

However, the directions of the association between DTF and yield were different among hybrids derived from different female parents. For hybrids derived from B010054 and B963676, there were more significantly positive associations; all four significant associations for the B010054 hybrids and seven of the eleven significant associations for the B963676 hybrids were positive. A similar trend was observed in the whole data set, positive associations were observed in 6 (i.e., 86\%) of the 7 B010054 trials and 15 (i.e., $71 \%$ ) of the 21 B963676 trials. In contrast, negative associations were present in four of the seven significant cases for B986604 hybrids. Similarly, in the whole data set, there were 10 negative and 9 positive associations between flowering time and grain yield for the B986604 hybrids.

The effect of DTF on grain yield was largely determined by the growing conditions, but also modified by the genetic background of female testers. Associations between DTF and yield showed the same direction for hybrids across female testers within 12 (positive in 8 and negative in 4) of the 20 AYTMales trials. In the remaining eight AYTMales trials, hybrids from different female parents displayed contrast directions of associations between flowering and yield in the same individual trials.

After accounting for the effect of DTF using Model 4, between-trial genetic correlations for yield ranged from -0.82 to 1 with a mean of 0.08 (Supplementary Table S4). Compared to the unadjusted between-trial genetic correlation of grain yield, adjusting for DTF did not improve the between-trial genetic correlation of yield. 
Table 4. Proportion of genetic yield variance explained by flowering time (DTF) and regression coefficient of DTF on grain yield of the 48 tester/trial combinations for the three female testers in the 21 trials.

\begin{tabular}{|c|c|c|c|c|c|c|c|c|c|c|c|c|c|}
\hline \multirow[b]{2}{*}{ Trial } & \multicolumn{4}{|c|}{ Female B010054 } & \multicolumn{4}{|c|}{ Female B963676 } & \multicolumn{4}{|c|}{ Female B986604 } & \multirow[b]{2}{*}{ ET } \\
\hline & $\begin{array}{c}\text { Mean Yield of } \\
\text { Female Specific } \\
\text { Hybrids t ha }{ }^{-1}\end{array}$ & $\begin{array}{l}\text { Genetic Yield } \\
\text { Contribution by } \\
\text { DTF }(\%)^{\text {a }}\end{array}$ & $\begin{array}{l}\text { Regression } \\
\text { Coefficient }\end{array}$ & se & $\begin{array}{c}\text { Mean Yield of } \\
\text { Female Specific } \\
\text { Hybrids tha }^{-1}\end{array}$ & $\begin{array}{l}\text { Genetic Yield } \\
\text { Contribution by } \\
\text { DTF (\%) }\end{array}$ & $\begin{array}{l}\text { Regression } \\
\text { Coefficient }\end{array}$ & se & $\begin{array}{c}\text { Mean Yield of } \\
\text { Female Specific } \\
\text { Hybrids } \mathrm{t} \mathrm{ha}^{-1}\end{array}$ & $\begin{array}{c}\text { Genetic Yield } \\
\text { Contribution by } \\
\text { DTF }(\%)^{\mathrm{a}}\end{array}$ & $\begin{array}{l}\text { Regression } \\
\text { Coefficient }\end{array}$ & se & \\
\hline PYTM15WAR & $-b$ & - & - & - & 7.54 & ns & -0.02 & 0.02 & - & - & - & - & 1 \\
\hline AYTM15CAP & 3.00 & $\mathrm{Ns}^{\mathrm{c}}$ & 0.02 & 0.03 & 3.00 & ns & 0.04 & 0.03 & 3.01 & ns & -0.01 & 0.06 & 4 \\
\hline AYTM15DAL & 6.93 & 5.4 & $\underline{0.19} \mathrm{e}^{\mathrm{e}}$ & 0.06 & 7.64 & 12.1 & $\underline{0.17}$ & 0.06 & 6.88 & ns & 0.16 & 0.13 & na \\
\hline AYTM15EME & 2.80 & ns & 0.02 & 0.05 & 3.23 & ns & $\overline{0.05}$ & 0.04 & 3.62 & ns & 0.08 & 0.09 & 2 \\
\hline AYTM15GAT & 5.73 & 11.1 & $\underline{0.17}$ & 0.07 & 6.67 & 11.2 & $\underline{0.19}$ & 0.06 & 6.48 & ns & $\underline{0.47}$ & 0.15 & 1 \\
\hline AYTM15WAR & 5.99 & ns & $\overline{\underline{0.13}}$ & 0.06 & 7.55 & ns & $\overline{0.08}$ & 0.05 & 7.74 & ns & $\overline{0.04}$ & 0.12 & 1 \\
\hline AYTM15JIM & 4.01 & 4.4 & $\underline{0.15}$ & 0.05 & 4.45 & ns & 0.08 & 0.04 & 4.92 & ns & -0.02 & 0.10 & na \\
\hline AYTM15SPR & 6.79 & ns & -0.01 & 0.06 & 6.81 & ns & -0.10 & 0.05 & 7.06 & ns & 0.11 & 0.13 & na \\
\hline AYTM16CRO & - & ns & - & - & 5.66 & ns & $\overline{0.05}$ & 0.03 & 5.76 & ns & 0.04 & 0.04 & na \\
\hline AYTM16DAL & - & ns & - & - & 6.70 & $-61.0^{\mathrm{d}}$ & -0.27 & 0.03 & 6.41 & -44.5 & -0.34 & 0.04 & 1 \\
\hline AYTM16EME & - & ns & - & - & 2.41 & -2.1 & $-\underline{-0.10}$ & 0.04 & 2.87 & $\mathrm{~ns}$ & $-\underline{-0.11}$ & 0.04 & na \\
\hline AYTM16WAR & - & ns & - & - & 7.55 & 9.5 & $\underline{\underline{0.18}}$ & 0.05 & 6.92 & -0.2 & $-\overline{\underline{0.13}}$ & 0.05 & 1 \\
\hline AYTM16JAN & - & ns & - & - & 5.34 & ns & $\overline{0.07}$ & 0.04 & 5.33 & 3.9 & 0.15 & 0.05 & 1 \\
\hline AYTM16ORI & - & ns & - & - & 2.66 & 13.6 & $\underline{0.08}$ & 0.02 & 3.14 & ns & $\frac{0.00}{0.00}$ & 0.03 & na \\
\hline AYTM16PIR & - & ns & - & - & 6.41 & 5.5 & $\overline{0.09}$ & 0.03 & 6.38 & ns & -0.05 & 0.03 & 2 \\
\hline AYTM16SPR & - & ns & - & - & 6.21 & ns & 0.08 & 0.04 & 5.84 & ns & -0.01 & 0.04 & na \\
\hline AYTM17EME & - & ns & - & - & 6.18 & ns & $\frac{0.10}{0.10}$ & 0.06 & 6.09 & ns & 0.06 & 0.06 & na \\
\hline AYTM17PIN & - & ns & - & - & 4.88 & -6.7 & $-\underline{0.11}$ & 0.03 & 5.30 & ns & $-\underline{0.10}$ & 0.04 & 5 \\
\hline AYTM17CAR & - & ns & - & - & 3.60 & -12.2 & $-\overline{0.16}$ & 0.03 & 3.59 & ns & $-\overline{0.08}$ & 0.04 & 5 \\
\hline AYTM17MAC & - & ns & - & - & 4.00 & ns & $\overline{0.02}$ & 0.03 & 3.77 & ns & 0.09 & 0.04 & 1 \\
\hline
\end{tabular}

${ }^{a}$ Values estimated by modelling male parents within female parents; ${ }^{b}$ results were not presented due to very limited sample size for these two combinations with PYTM15WAR; ${ }^{c}$ ns indicates the DTF effect on yield of male parents was not significant, therefore the genetic yield contribution cannot be estimated and was not presented; ${ }^{\mathrm{d}}$ negative values indicate negative effect of DTF on yield of male lines; ${ }^{\mathrm{e}}$ values in bold and underlined text indicates significant DTF effects on yield of hybrids; ${ }^{\mathrm{f}}$ ET1 (environment type 1) indicates no or low water stress on average throughout the crop life cycle, ET2 indicates water stress did not occur until after flowering with mild water stress at the end of the crop cycle, ET5 experienced water stress starting from anthesis while water stress occurred well before flowering and more severely in ET4, na indicates ET data not available. 


\subsection{Impact of FTN on Grain Yield}

Genetic yield contribution by FTN of male lines was significant in 12 of the 48 tester/trial combinations, with six significant each for male lines crossed with B93676 and B986604 (Table 5). Similar to that of DTF, the proportion of genetic yield variation explained by models including FTN as a fixed effect varied across trials and female parents. Absolute values of the genetic yield contribution by FTN ranged between $1.4 \%$ and $56.9 \%$, with an average of $18.3 \%$ for those tester/trial combinations with a significant FTN contribution.

Linear regression analysis showed that a statistically significant association between FTN and grain yield of hybrids was observed in 12 tester/trial combinations, of which nine were positive (Table 5). The general trend towards a positive association between FTN and yield remained somewhat evident in the data set as a whole, with 26 associations being positive and 21 negative. Significant associations between FTN and yield were observed in 5 tester/trial combinations that experienced ET1 and in 1 tester/trial combination, which experienced ET4. Unlike the relationship between DTF and yield, a significantly negative association was slightly more often observed than a significantly positive association (i.e., 3 vs. 2 tester/trial combinations) in ET1; however, a significantly positive relationship of FTN to yield was observed in ET4.

Similar to the finding for DTF and grain yield, the number of positive and negative associations between FTN and yield varied across hybrids derived from different female testers. For hybrids in combination with B963676 and B986604, there was a general trend of positive relationships, with five and four of the six significant cases being positive, respectively. The trend towards a positive association between FTN and grain yield for the B963676 and B986604 hybrids was confirmed in the whole data sets of the corresponding tester groups, with 13 and 11 associations being positive and 8 associations being negative. In contrast, for B010054 hybrids, a negative association was observed on five occasions and positive in the other two, though none was significant.

Although the directions of the associations of FTN and yield varied across tester/trial combinations, the effect of FTN on yield was largely determined by the environmental conditions, and to a lesser extent, modified by the genetic background of female testers. Associations between FTN and yield showed the same direction for hybrids across female parents within 13 (all positive in 8 and negative in 5) of the 20 AYTMales trials. For the remaining seven AYTMales trials, the directions of the associations for hybrids across female parents differed.

After accounting for the effect FTN using Model 5, the between-trial genetic correlations for yield ranged from -0.79 to 1 with a mean of 0.06 (Supplementary Table S5). Compared to the unadjusted between-trial genetic correlation for yield, adjusting for FTN did not improve all of the between-trial correlations. 
Table 5. Proportion of genetic yield variance explained by fertile tiller number per plant (FTN) and regression coefficient of FTN on grain yield of the 48 tester/trial combinations for the three female testers in the 21 trials.

\begin{tabular}{|c|c|c|c|c|c|c|c|c|c|c|c|c|c|}
\hline \multirow[b]{2}{*}{ Trial } & \multicolumn{4}{|c|}{ Female B010054 } & \multicolumn{4}{|c|}{ Female B963676 } & \multicolumn{4}{|c|}{ Female B986604 } & \multirow[b]{2}{*}{ ET } \\
\hline & $\begin{array}{c}\text { Mean Yield of } \\
\text { Female Specific } \\
\text { Hybrids t ha }{ }^{-1}\end{array}$ & $\begin{array}{l}\text { Genetic Yield } \\
\text { Contribution by } \\
\text { FTN }(\%)^{\mathrm{a}}\end{array}$ & $\begin{array}{l}\text { Regression } \\
\text { Coefficient }\end{array}$ & se & $\begin{array}{c}\text { Mean Yield of } \\
\text { Female Specific } \\
\text { Hybrids tha }^{-1}\end{array}$ & $\begin{array}{l}\text { Genetic Yield } \\
\text { Contribution by } \\
\text { FTN (\%) }\end{array}$ & $\begin{array}{l}\text { Regression } \\
\text { Coefficient }\end{array}$ & se & $\begin{array}{c}\text { Mean Yield of } \\
\text { Female Specific } \\
\text { Hybrids } \mathrm{t} \mathrm{ha}^{-1}\end{array}$ & $\begin{array}{l}\text { Genetic Yield } \\
\text { Contribution by } \\
\text { FTN }(\%)^{\mathrm{a}}\end{array}$ & $\begin{array}{l}\text { Regression } \\
\text { Coefficient }\end{array}$ & se & \\
\hline PYTM15WAR & $-b$ & - & - & - & 7.54 & $-6.1^{\mathrm{d}}$ & $-0.16^{\mathrm{e}}$ & 0.07 & - & - & - & - & 1 \\
\hline AYTM15CAP & 3.00 & $\mathrm{~ns}^{\mathrm{c}}$ & -0.38 & 0.21 & 3.00 & ns & 0.33 & 0.17 & 3.01 & ns & -0.17 & 0.39 & 4 \\
\hline AYTM15DAL & 6.93 & ns & -0.43 & 0.46 & 7.64 & ns & $\overline{0.09}$ & 0.39 & 6.88 & ns & 0.53 & 0.97 & na \\
\hline AYTM15EME & 2.80 & ns & 0.07 & 0.33 & 3.23 & ns & -0.13 & 0.29 & 3.62 & ns & 0.00 & 0.63 & 2 \\
\hline AYTM15GAT & 5.73 & ns & 0.02 & 0.50 & 6.67 & ns & 0.69 & 0.42 & 6.48 & ns & 0.57 & 1.32 & 1 \\
\hline AYTM15WAR & 5.99 & ns & -0.26 & 0.43 & 7.55 & ns & -0.16 & 0.35 & 7.74 & ns & -0.67 & 0.83 & 1 \\
\hline AYTM15JIM & 4.01 & ns & -0.28 & 0.35 & 4.45 & ns & -0.45 & 0.30 & 4.92 & ns & -0.87 & 0.73 & na \\
\hline AYTM15SPR & 6.79 & ns & -0.79 & 0.41 & 6.81 & ns & 0.04 & 0.36 & 7.06 & ns & 0.86 & 0.89 & na \\
\hline AYTM16CRO & - & ns & - & - & 5.66 & 56.9 & $\overline{1.16}$ & 0.23 & 5.76 & 31.0 & $\overline{0.73}$ & 0.27 & na \\
\hline AYTM16DAL & - & ns & - & - & 6.70 & $\mathrm{~ns}$ & $\underline{-0.47}$ & 0.26 & 6.41 & ns & $\overline{-0.10}$ & 0.27 & 1 \\
\hline AYTM16EME & - & ns & - & - & 2.41 & ns & -0.26 & 0.30 & 2.87 & ns & 0.10 & 0.30 & na \\
\hline AYTM16WAR & - & ns & - & - & 7.55 & -2.5 & -0.70 & 0.36 & 6.92 & -7.6 & -0.77 & 0.37 & 1 \\
\hline AYTM16JAN & - & ns & - & - & 5.34 & ns & 0.34 & 0.27 & 5.33 & -4.0 & -1.13 & 0.32 & 1 \\
\hline AYTM16ORI & - & ns & - & - & 2.66 & ns & 0.10 & 0.16 & 3.14 & ns & $\overline{0.21}$ & 0.19 & na \\
\hline AYTM16PIR & - & ns & - & - & 6.41 & ns & -0.28 & 0.22 & 6.38 & ns & -0.01 & 0.22 & 2 \\
\hline AYTM16SPR & - & ns & - & - & 6.21 & 32.0 & 1.04 & 0.26 & 5.84 & 1.4 & $\underline{0.58}$ & 0.27 & na \\
\hline AYTM17EME & - & ns & - & - & 6.18 & ns & 0.12 & 0.44 & 6.09 & $\mathrm{~ns}$ & 0.26 & 0.46 & na \\
\hline AYTM17PIN & - & ns & - & - & 4.88 & ns & 0.54 & 0.28 & 5.30 & ns & 0.28 & 0.30 & 5 \\
\hline AYTM17CAR & - & ns & - & - & 3.60 & ns & 0.30 & 0.27 & 3.59 & ns & -0.23 & 0.30 & 5 \\
\hline AYTM17MAC & - & ns & - & - & 4.00 & 23.5 & 0.91 & 0.28 & 3.77 & 15.2 & 0.79 & 0.30 & 1 \\
\hline
\end{tabular}

${ }^{a}$ Values estimated by modelling male parents within female parents; ${ }^{b}$ results were not presented due to very limited sample size for these two combinations with PYTM15WAR; ${ }^{\mathrm{c}}$ ns indicates the FTN effect on yield of male parents was not significant, therefore the genetic yield contribution cannot be estimated and was not presented; ${ }^{\mathrm{d}}$ negative values indicate negative effect of FTN on yield of male lines; ${ }^{\mathrm{e}}$ values in bold and underlined text indicates significant FTN effects on yield of hybrids; ${ }^{\mathrm{f}}$ ET1 (environment type 1) indicates no or low water stress on average throughout the crop life cycle, ET2 indicates water stress did not occur until after flowering with mild water stress at the end of the crop cycle, ET5 experienced water stress starting from anthesis while water stress occurred well before flowering and more severely in ET4, na indicates ET data not available. 


\subsection{Relationships of DTF and FTN Effects to Mean Grain Yield}

The linear regression coefficient quantifying the relationship between DTF and yield for hybrids in combination with any of B010054, B963676, and B986604 was not related to the mean yield of the tester/trial combination (Figure 2; Table 4). However, for the B010054 hybrids, most associations (6 out of 7 trials) were positive. Similarly, there were generally more positive associations (15 of 21 trials) for B963676 hybrids. However, this was not obvious for B986604 hybrids, where the number of positive associations (9) was similar to the number of negative associations (11).

The linear regression coefficient quantifying the relationship between FTN and yield was also not related to the mean grain yield of the tester/trial combinations (Figure 2; Table 5). For B963676 and B986604 hybrids, the effect of FTN on yield was more likely to be positive, but the opposite trend was found for the B010054 hybrids, with the FTN effect on yield more likely to be negative.
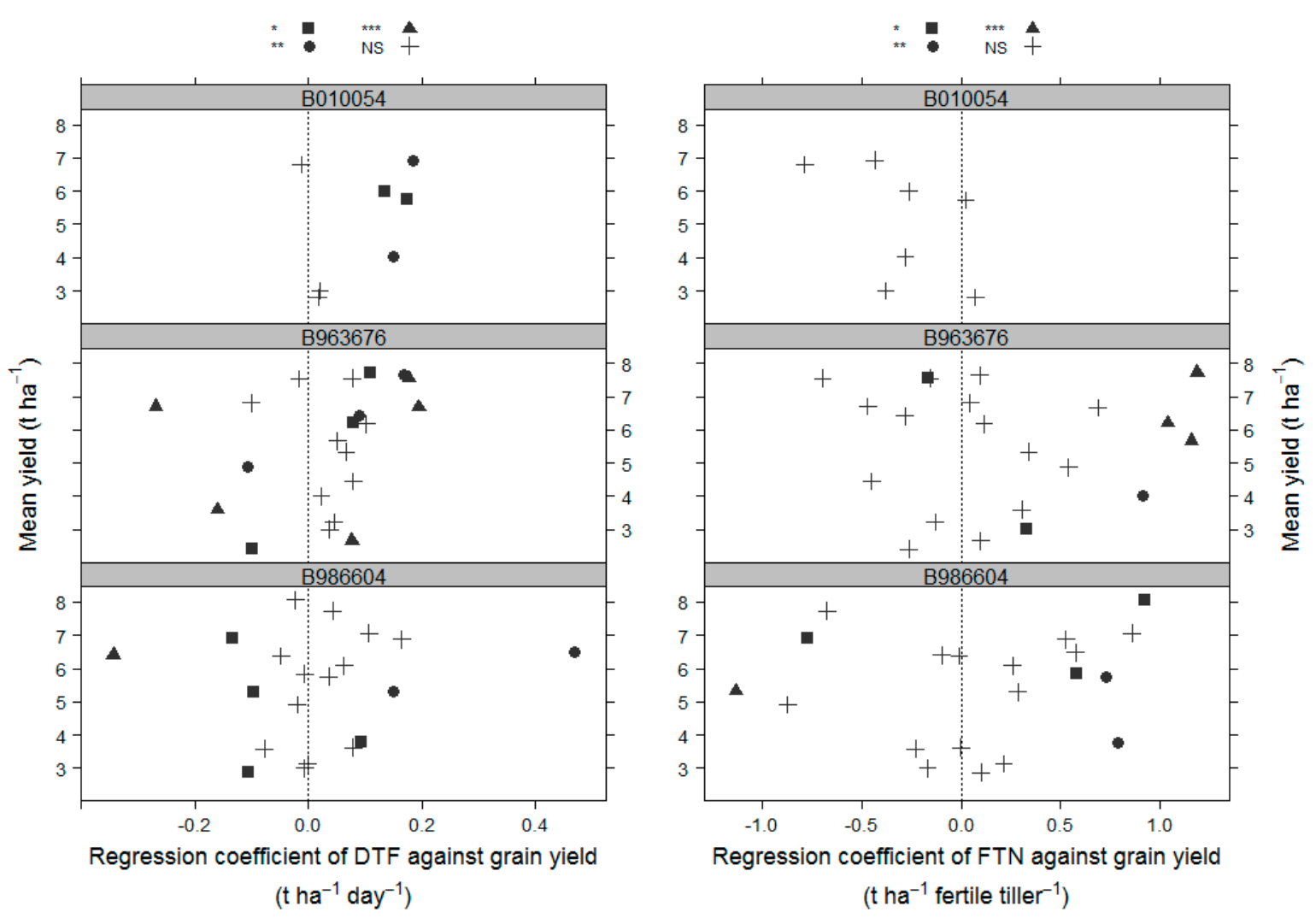

Figure 2. Mean grain yield of the hybrids plotted against the coefficients of the regression of flowering time (DTF) or fertile tiller number per plant (FTN) on grain yield in individual trials by female tester. NS indicates non-significant DTF or FTN effect, ${ }^{*}$ significant at the level of $p<0.05,{ }^{* *}$ significant at the level of $p<0.01{ }^{* * *}$ significant at the level of $p<0.001$; vertical dashed lines represent regression coefficient of 0 .

\section{Discussion}

Sorghum production environments in dryland conditions such as Australia are highly variable, particularly with regard to water availability during the growing season. DTF and FTN can contribute to variations in grain yield by altering canopy development dynamics, radiation interception and the temporal pattern of water use. Depending on the environment, both traits may have a positive or negative effect on sorghum grain yield and hence contribute to GEI for grain yield, which complicates selection and restricts genetic yield gain. In this study, we quantified the impacts of genetic variations in DTF and FTN on grain yield using data from 21 pre-breeding trials grown across the major sorghum production regions in Australia in three growing seasons. The dataset included 1741 unique test cross 
hybrids derived from 1078 elite male lines. The lines were representative of the Australian sorghum pre-breeding program. For the purposes of the study, sets of test cross hybrids grown in a single environment were considered as an experimental unit to explore the relationships between grain yield and the other two traits. The results provided insights that can be used to design breeding programs and to select cultivars targeting this variable environment.

\subsection{The Impacts of DTF and FTN on Grain Yield Varied across Environments}

The genetic variation in yield varied between sites $[11,33]$ with the model including the across site estimates of DTF and FTN being significant in only 15 and 12 of the 48 tester/trial combinations, respectively (Tables 4 and 5). The average percentage of genetic yield variance explained by the across site estimate of FTN was slightly greater at $18.3 \%$ than the $13.6 \%$ that was explained by DTF (Tables 4 and 5). This may be because in addition to its indirect effect on grain yield by influencing the canopy size [17-19], tillering can affect yield through its direct effect on the number of grain-bearing panicles [21], which can be exacerbated in situations of poor emergence. Previous studies have reported that fertile tillers can produce $5 \%-78 \%$ of grain yield depending on the population density [21].

In this study, we found that increased grain yield was often positively correlated with late flowering in environments experiencing low or mild water stress (e.g., ET1 and ET2) but negatively associated with flowering time in severe terminal drought situations (ET5). These results are consistent with previous studies $[8,24]$. Under well-watered conditions, biomass accumulation is radiation limited, such that prolonged phenology can increase canopy size (at least early in the season at low leaf area index), which increases light interception and hence biomass production and grain yield. However, in water-limited environments, plant size is not only limited but leaves may also senescence earlier and faster, leading to reduced grain yield. Hammer [14] demonstrated the extreme sensitivity of sorghum yield to water stress during the grain-filling period.

Contrast to the relationship of DTF to grain yield, increased grain yield was more often associated with reduced tillering in no or low water deficit conditions but associated with increased tillering in water stressed environments. The trend of FTN on yield observed in this study was also inconsistent with previous studies [8], which through simulations found that reduced tillers led to increased yield in terminal drought conditions but to reduced yield in favourable conditions with low or mild water stress. This inconsistency might be due to sampling error as only 5 trials (or 6 tester/trial combinations) having ET estimated showed a significant association between FTN and yield.

The more frequent detection and higher average genetic yield contribution of positive associations than that of negative associations suggested that the mean FTN observed in this study was potentially lower than optimal for the 48 tester/trial combinations in the Australian sorghum pre-breeding program sampled in this study. Regarding the relationship of DTF to yield, although the average genetic yield contribution of negative associations was higher than that of positive associations, which was due to very high genetic yield contributions (i.e., $61.0 \%$ and $44.5 \%$ ) in a single trial (i.e., AYTM16DAL), positive associations were more frequently detected. This result might also indicate that the mean DTF for the set of genotypes was potentially earlier than optimal for the environments sampled in this study. These indications may be related to sorghum breeders needing to select for broad adaption, therefore, taking a conservative approach to selection for maturity and tillering. Sorghum is highly sensitive to post-flowering drought and the approach of selecting for early maturing and/or low tillering genotypes reduces the risk of yield penalty under post-anthesis drought. Alternatively, it may be that the environments sampled by these trials are not a good representative sample of the target population of environments. Given that the average yield of grain sorghum was $2.90 \mathrm{t} \mathrm{ha}^{-1}$ in Australia during the 2015-2017 seasons [34,35] and the mean yield of the trials in this study was $5.50 \mathrm{tha}^{-1}$, the latter may have been the case. However, part of the reason that high-yielding environments were over-sampled in our data set and only one trial had a mean yield less than the average yield in Australia is that our program tends to sample trials with reasonable stored soil moisture to reduce the chance of crop failure. In addition, many low yielding trials that would be harvested by farmers were failures as 
experiments and data were not collected or could not be used (e.g., no genetic variation due to very high error, extreme lodging).

Despite this, trial mean yield was not a good predictor of associations between DTF, FTN and yield. Results in this study suggested that the associations between DTF and yield, FTN and yield were not related to the mean yield of the combinations. Approximately equal amounts of positive and negative associations were detected in either high or low yielding environments for hybrids derived from all testers except B010054. Previously, Jordan et al. [1] investigated the role of stay-green on grain yield using hybrids from the same sorghum pre-breeding program. They found that the majority of associations between stay-green and grain yield were positive for trials with a mean yield of less than $6 \mathrm{tha}^{-1}$ and there were similar amounts of positive and negative associations for trials with a mean yield of between 6 and $9 \mathrm{tha}^{-1}$. As reduced tillering could result in the expression of stay-green via potential restriction of pre-anthesis water use [16], this might indicate that reduced tiller number would positively correlate with increased yield for trials with a mean yield under $6 \mathrm{tha}^{-1}$. However, this was not observed in this study (Figure 2). This contrast may be because the stay-green trait can improve yield under drought conditions by reducing plant size at anthesis through a number of mechanisms other than reducing tillering, which included reducing leaf number of the main stem, increasing sizes of upper leaves of the main stem [12,13], and accelerating age-related senescence of lower leaves [36].

\subsection{The Impacts of DTF and FTN on Grain Yield were Also Affected by the Genetic Background of Female Testers}

Although the impact of environmental conditions had the largest effect on the association between DTF, FTN and yield, the frequency of significant associations varied across the genetic background of female testers. The directions of the associations between DTF and yield, FTN and yield for hybrids derived from different female testers of the same trial were the same in 12 and 13, respectively, of the 20 AYTMales trials (Tables 4 and 5). Contrasting directions of associations between DTF and yield, FTN and yield for hybrids derived from different female testers were observed in the other eight and seven AYTMales trials, respectively. The three testers have similar flowering dates but possess various degrees of stay-green and differ in tillering capacity (Table 1). Hence, it is very likely that they have different patterns of canopy development and water uptake. These differences consequently complicate the relationships of DTF and FTN with grain yield.

\subsection{Implications for Breeding Programs}

This study is the most extensive analysis of the impacts of DTF and FTN on grain yield of hybrid sorghum published to date. By using a dataset of over 1700 sorghum hybrids from different genetic background grown across diverse production environments in Australia, this study provides an example of using results from a large number of independent trials (with differing genetic materials and environments) for examing the impacts of DTF and FTN on the yield of grain sorghum. Breeding lines evaluated in the Australian sorghum pre-breeding program represented the genetic diversity of the commercial sorghum hybrids grown by farmers, and the testing environments sampled in this study were a good representation of the target population of growth environments in Australia. Therefore, the findings in this study provide valuable insights into the design of sorghum breeding programs and selection of hybrids targeting this variable environment varying in water availability. Although breeding lines of the Australian sorghum pre-breeding program were developed from global sorghum accessions, the materials evaluated in this study have little photoperiod sensitivity; hence, the findings of this study are more relevant to enviornments where photoperiod insensitive cultivars are grown such as in the USA. Additionally, due to the small sample size of characterised environments, with only 3 of the 21 trials characterised as experiencing very severe water deficit (ET4 and ET5), the impacts of DTF and FTN on sorghum grain yield under drought condifition might be different to the results identified in this study. 
The relationships of DTF and FTN with grain yield were modified somewhat by the genetic background of female parents. Hybrids with $\mathrm{B} 963676$ as a female parent had positive associations between DTF and yield, FTN and yield more often than hybrids from the other two parents. This result reinforces the importance of the selection of specific female parents in hybrid breeding.

As independent traits, DTF and FTN were expected to show similar directions of associations with grain yield as they are expected to influence water use similarly. This was supported by the observation that DTF and FTN displayed the same directions of association with yield in 28 of the 48 tester/trial combinations (Tables 4 and 5). However, static values of DTF and FTN, while indicative, do not provide robust estimates of the dynamics of canopy size and duration throughout the whole crop life cycle. The use of recent developments in high throughput phenotyping platforms to capture canopy development dynamics during the crop life cycle is likely to enhance the understanding and analysis of GEI on yield [37].

In this study, the rationale for attempting to account for the confounding effects of DTF and FTN on grain yield was to partition the GEI for grain yield caused by canopy size and duration into more heritable components that interact with the environment in complex ways. However, within the materials and environments studied, the impacts of DTF and FTN on grain yield were low. Following adjustment for variation in emergence, substantial GEI remained after further incorporating the effects of DTF and FTN in the linear mixed model analysis. This was indicated by the low genetic correlation for yield between trials following the incorporation of DTF and FTN (Supplementary Tables S4 and S5). It is possible that this inability to further partition GEI was associated with the use of linear mixed models for the analysis of genetic effects on yield. Linear mixed models assume linear relationships of yield with DTF and FTN, whereas it is known that these effects are non-linear in their generation of GEI. To overcome this defect, crop simulation models such as the sorghum module [31] implemented in the APSIM platform [32] might be implemented to better account for the impacts of DTF and FTN on yield and to dissect the GEI generated by canopy development dynamics due to differences in DTF and FTN. However, it is also likely that other genetic factors, such as those affecting radiation use efficiency, transpiration efficiency, root angle, height, seed number, and seed size play important roles in determining grain yield and generating GEIs for grain yield. This was supported by the observation of the contrasting directions of associations of DTF and FTN with yield observed in 20 of the 48 tester/trial combinations. While general trends were observed, it is clear that the complex milieu of traits and environments and their dynamic interactions to generate GEIs could not be simply deconstructed via the key major factors (DTF and FTN) known to affect canopy development and duration. However, advances in the more integrated use of crop growth models in conjunction with genomic selection [38] suggest the possibility for enhanced leveraging of biological insight across multiple adaptive traits in the pursuit of more rapid genetic gain in situations with confounding GEI.

Supplementary Materials: The following are available online at http://www.mdpi.com/2073-4395/10/1/135/s1, Figure S1: Between trial genetic correlations of flowering time (DTF), number of fertile tillers per plant (FTN), and grain yield. Figrue S2: Flowering time of hybrids by female testers for the 17 trials. Figure S3: Number of fertile tillers per plant (FTN) of hybrids by female testers for the 11 trials. Figure S4: Grain yield of hybrids by female testers for the 21 trials. Table S1: Details of the 21 trials and the number of hybrid combinations for each female tester in the 2015-17 summer growing seasons. Table S2: Between trial genetic correlations of grain yield adjusted for establishment. Table S3: Correlation of overall BLUPs for flowering time (DTF) and fertile tiller number per plant (FTN) for hybrids in combination with the three female testers. Table S4: Between trial genetic correlations of grain yield after accounting for the effect of flowering time (DTF). Table S5: Between trial genetic correlations of grain yield after accounting for the effect of fertile tiller number per plant (FTN).

Author Contributions: X.W., D.J., and G.H. conceived the project. X.W. collected data of fertile tiller number per plant and conducted all the analyses except predicting overall BLUPs for DTF and FTN from MET analyses. C.H. conducted MET analyses to predict overall BLUPs for DTF and FTN. A.C. recorded flowering time. X.W. wrote the manuscript. The other authors read the manuscript. All authors have read and agreed to the published version of the manuscript.

Funding: This research was funded by Grains Research and Development Corporation (GRDC), grant number UQ00070. 
Acknowledgments: We would like to acknowledge the sorghum pre-breeding team at Hermitage Research Facility for support of the field trials. We thank Greg McLean at the Queensland Department of Agriculture and Fisheries (DAF) for his help in data interpretation. X.W. is financially supported by an Australian Government Research Training Program (RTP) Scholarship and a Centennial Scholarship (UQCent) from The University of Queensland (UQ). This study is supported by DAF, UQ, and the GRDC sorghum pre-breeding project.

Conflicts of Interest: The authors declare no conflict of interest.

\section{References}

1. Jordan, D.R.; Hunt, C.H.; Cruickshank, A.W.; Borrell, A.K.; Henzell, R.G. The relationship between the stay-green trait and grain yield in elite sorghum hybrids grown in a range of environments. Crop Sci. 2012, 52, 1153-1161. [CrossRef]

2. Passioura, J.B.; Angus, J.F. Improving productivity of crops in water-limited environments. Adv. Agron. 2010, 106, 37-75. [CrossRef]

3. Chenu, K.; Cooper, M.; Hammer, G.L.; Mathews, K.L.; Dreccer, M.F.; Chapman, S.C. Environment characterization as an aid to wheat improvement: Interpreting genotype-environment interactions by modelling water-deficit patterns in North-Eastern Australia. J. Exp. Bot. 2011, 62, 1743-1755. [CrossRef] [PubMed]

4. Bandaru, V.; Stewart, B.A.; Baumhardt, R.L.; Ambati, S.; Robinson, C.A.; Schlegel, A. Growing dryland grain sorghum in clumps to reduce vegetative growth and increase yield. Agron. J. 2006, 98, 1109-1120. [CrossRef]

5. Heinemann, A.B.; Dingkuhn, M.; Luquet, D.; Combres, J.C.; Chapman, S. Characterization of drought stress environments for upland rice and maize in central Brazil. Euphytica 2008, 162, 395-410. [CrossRef]

6. Kholová, J.; Mclean, G.; Vadez, V.; Craufurd, P.; Hammer, G.L. Drought stress characterization of post-rainy season (rabi) sorghum in India. Field Crops Res. 2013, 141, 38-46. [CrossRef]

7. Chapman, S.C.; Cooper, M.; Hammer, G.L.; Butler, D.G. Genotype by environment interactions affecting grain sorghum. II. Frequencies of different seasonal patterns of drought stress are related to location effects on hybrid yields. Aust. J. Agric. Res. 2000, 51, 209-221. [CrossRef]

8. Hammer, G.L.; McLean, G.; Chapman, S.; Zheng, B.; Doherty, A.; Harrison, M.T.; van Oosterom, E.; Jordan, D. Crop design for specific adaptation in variable dryland production environments. Crop Pasture Sci. 2014, 65, 614-626. [CrossRef]

9. Lake, L.; Chenu, K.; Sadras, V.O. Patterns of water stress and temperature for Australian chickpea production. Crop Pasture Sci. 2016, 67, 204-215. [CrossRef]

10. Chapman, S.C.; Hammer, G.L.; Butler, D.G.; Cooper, M. Genotype by environment interactions affecting grain sorghum. III. Temporal sequences and spatial patterns in the target population of environments. Aust. J. Agric. Res. 2000, 51, 223-233. [CrossRef]

11. Chapman, S.C.; Cooper, M.; Butler, D.G.; Henzell, R.G. Genotype by environment interactions affecting grain sorghum. I. Characteristics that confound interpretation of hybrid yield. Aust. J. Agric. Res. 2000, 51, 197-207. [CrossRef]

12. Borrell, A.K.; van Oosterom, E.J.; Mullet, J.E.; George-Jaeggli, B.; Jordan, D.R.; Klein, P.E.; Hammer, G.L. Stay-green alleles individually enhance grain yield in sorghum under drought by modifying canopy development and water uptake patterns. New Phytol. 2014, 203, 817-830. [CrossRef] [PubMed]

13. Borrell, A.K.; Mullet, J.E.; George-Jaeggli, B.; Van Oosterom, E.J.; Hammer, G.L.; Klein, P.E.; Jordan, D.R. Drought adaptation of stay-green sorghum is associated with canopy development, leaf anatomy, root growth, and water uptake. J. Exp. Bot. 2014, 65, 6251-6263. [CrossRef] [PubMed]

14. Hammer, G.L. Pathways to prosperity: Breaking the yield barrier in sorghum. Agric. Sci. 2006, 19, 16-22.

15. Ravi Kumar, S.; Hammer, G.L.; Broad, I.; Harland, P.; McLean, G. Modelling environmental effects on phenology and canopy development of diverse sorghum genotypes. Field Crops Res. 2009, 111, 157-165. [CrossRef]

16. van Oosterom, E.J.; Borrell, A.K.; Deifel, K.S.; Hammer, G.L. Does increased leaf appearance rate enhance adaptation to postanthesis drought stress in sorghum? Crop Sci. 2011, 51, 2728-2740. [CrossRef]

17. Hammer, G.L.; Hill, K.; Schrodter, G.N. Leaf area production and senescence of diverse grain sorghum hybrids. Field Crops Res. 1987, 17, 305-317. [CrossRef]

18. Kim, H.K.; Luquet, D.; van Oosterom, E.; Dingkuhn, M.; Hammer, G. Regulation of tillering in sorghum: Genotypic effects. Ann. Bot. 2010, 106, 69-78. [CrossRef] 
19. van Oosterom, E.; Hammer, G.; Kim, H.-K.; Mclean, G.; Deifel, K. Plant design features that improve grain yield of cereals under drought. In Glob. Issues, Paddock Action, Proceedings of the 14th Australian Agronomy Conference, Adelaide, Australia, 21-25 September 2008; The Regional Institute: Gosford, Australia, 2008.

20. Lafarge, T.A.; Hammer, G.L. Tillering in grain sorghum over a wide range of population densities: Modelling dynamics of tiller fertility. Ann. Bot. 2002, 90, 99-110. [CrossRef]

21. Lafarge, T.A.; Broad, I.J.; Hammer, G.L. Tillering in grain sorghum over a wide range of population densities: Identification of a common hierarchy for tiller emergence, leaf area development and fertility. Ann. Bot. 2002, 90, 87-98. [CrossRef]

22. Fischer, K.S.; Edmeades, G.O.; Johnson, E.C. Selection for the improvement of maize yield under moisture-deficits. Field Crops Res. 1989, 22, 227-243. [CrossRef]

23. Alam, M.M.; van Oosterom, E.J.; Cruickshank, A.W.; Jordan, D.R.; Hammer, G.L. Predicting tillering of diverse sorghum germplasm across environments. Crop Sci. 2017, 57, 78-87. [CrossRef]

24. Dalton, L.G. A positive regression of yield on maturity in sorghum. Crop Sci. 1967, 7, 271. [CrossRef]

25. Saeed, M.; Francis, C.A. Yield-maturity relationship of grain sorghum in diverse environments. Crop Sci. 1986, 26, 1077-1079. [CrossRef]

26. Cullis, B.R.; Smith, A.B.; Coombes, N.E. On the design of early generation variety. J. Agric. Biol. Environ. Stat. 2006, 11, 381-393. [CrossRef]

27. Smith, A.; Cullis, B.; Thompson, R. Analyzing variety by environment data using multiplicative mixed models and adjustments. Biometrics 2001, 57, 1138-1147. [CrossRef]

28. Butler, D.G.; Cullis, B.R.; Gilmour, A.R.; Gogel, B.J. ASReml-R Reference Manual, Version 3.0. 2009. Available online: http://www.vsn-intl.com/products/asreml/ (accessed on 16 September 2019).

29. R Core Team. R: A Language and Environment for Statistical Computing; Version 3.3.2; R Foundation for Statistical Computing: Vienna, Austria, 2016; Available online: https://www.R-project.org/ (accessed on 16 September 2019).

30. RStudio Team. RStudio: Integrated Development for R; Version 1.1.456; RStudio, Inc.: Boston, MA, USA, 2016; Available online: http://www.rstudio.com/ (accessed on 16 September 2019).

31. Hammer, G.L.; van Oosterom, E.; McLean, G.; Chapman, S.C.; Broad, I.; Harland, P.; Muchow, R.C. Adapting APSIM to model the physiology and genetics of complex adaptive traits in field crops. J. Exp. Bot. 2010, 61, 2185-2202. [CrossRef]

32. Holzworth, D.P.; Huth, N.I.; Peter, G.; Zurcher, E.J.; Herrmann, N.I.; Mclean, G.; Chenu, K.; van Oosterom, E.J.; Snow, V.; Murphy, C.; et al. APSIM-Evolution towards a new generation of agricultural systems simulation. Environ. Model. Softw. 2014, 62, 327-350. [CrossRef]

33. Chapman, S.C.; Cooper, M.; Hammer, G.L. Using crop simulation to generate genotype by environment interaction effects for sorghum in water-limited environments. Aust. J. Agric. Res. 2002, 53, 379-389. [CrossRef]

34. Cameron, A.; Xia, C.; Whitnall, T.; Miller, M.; Brown, A.; Agbenyegah, B.K.; Pitts, N. Australian Crop Report No. 187; Australian Bureau of Agricultural and Resource Economics and Sciences: Canberra, Australia, September 2018. Available online: www.daff.gov.au/abares/publications (accessed on 3 January 2019).

35. Agbenyegah, B.; Brown, A.; Cameron, A.; Mansfield, D.; Perndt, N.; Pitts, N.; Price, C.; Smith, S.; Xia, C. Australian Crop Report No. 182; Australian Bureau of Agricultural and Resource Economics and Sciences: Canberra, Australia, June 2017. Available online: https://data.gov.au/dataset (accessed on 16 October 2017).

36. George-Jaeggli, B.; Mortlockb, M.Y.; Borrell, A.K. Bigger is not always better: Reducing leaf area helps stay-green sorghum use soil water more slowly. Environ. Exp. Bot. 2017, 138, 119-129. [CrossRef]

37. Potgieter, A.B.; George-Jaeggli, B.; Chapman, S.C.; Laws, K.; Cadavid, L.A.S.; Wixted, J.; Watson, J.; Eldridge, M.; Jordan, D.R.; Hammer, G.L. Multi-spectral imaging from an unmanned aerial vehicle enables the assessment of seasonal leaf area dynamics of sorghum breeding. Front. Plant Sci. 2017, 8, 1-11. [CrossRef] [PubMed]

38. Messina, C.D.; Technow, F.; Tang, T.; Totir, R.L.; Gho, C.; Cooper, M. Leveraging biological insight and environmental variation to improve phenotypic prediction: Integrating crop growth models (CGM) with whole genome prediction (WGP). Eur. J. Agron. 2018, 100, 151-162. [CrossRef]

(C) 2020 by the authors. Licensee MDPI, Basel, Switzerland. This article is an open access article distributed under the terms and conditions of the Creative Commons Attribution (CC BY) license (http://creativecommons.org/licenses/by/4.0/). 